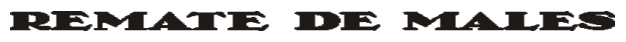

Campinas-SP, v.4o, n.2, pp. 433-442, jul./dez. 2020

\title{
DESCRIÇÃO E DESTRUIÇÃo
}

\section{DESCRIPTION AND DESTRUCTION}

\author{
Marco A. Bazzocchi ${ }^{1}$
}

Resumo: Para refletir sobre a relação entre escrita e sexualidade pela perspectiva de Pasolini, o presente artigo abordará as resenhas literárias publicadas pelo autor e reunidas postumamente no volume Descrizioni di descrizioni, passando também por suas outras produções, como o romance Petrolio e o filme Salò ou 120 dias de Sodoma. Valendo-se da ideia de que toda crítica é um ato obsceno, a intenção principal é pensar como o processo de escrita implica simultaneamente um gesto de criação e de destruição.

Palavras-chave: Pier Paolo Pasolini; Descrizioni di descrizioni; sexualidade.

Abstract: In order to inquire into the relation between writing and sexuality according to Pasolini, this essay will investigate the literary reviews, written by the author and posthumously collected in the book Descrizioni di descrizioni, as well as the novel Petrolio and the film Salò o le 120 giornate di Sodoma. Considering that, for Pasolini, every critique is an obscene act, the main goal in this essay is to explore how the process of writing results simultaneously in a gesture of creation and destruction.

Keywords: Pier Paolo Pasolini; Descrizioni di descrizioni; Sexuality.

O conceito de crítica de Pasolini baseia-se na presença simultânea de dois princípios opostos: o princípio da intuição irracional, que podemos identificar na estilística de Spitzer, e o princípio da crítica marxista, histórica, que podemos remeter a Gramsci. Em uma série de artigos jornalísticos dos anos 1960, Pasolini afirma a conjunção necessária entre estilística e marxismo, mas também fala da necessidade de um novo método para a crítica. Há contudo, em se tratando de Pasolini, mais dois

${ }^{1}$ Professor Emérito do Departamento de Filologia Clássica e Italianística da Universidade de Bolonha, Itália. 
nomes sempre citados: Gianfranco Contini e Roberto Longhi. Para mim, não é fácil identificar as perspectivas Contini e Longhi nas páginas da crítica pasoliniana. Pode-se dizer, como em Proust, que frequentemente pensamos percorrer o caminho de Swann e chegamos em Guermantes: os dois percursos se misturam, se unificam, irão se juntar.

Sabemos que nos textos curtos, reunidos sob o título Descrizioni di descrizioni após a morte do autor, há páginas sobre Longhi e Contini. São as últimas coisas escritas por Pasolini sobre os autores mais importantes de sua formação intelectual. E é sabido que os últimos desenhos feitos por ele são autorretratos e que há neles algo de Longhi, isto é, em um jogo de citação, Pasolini, em seu desenho, parte da capa do volume que reúne os escritos de Longhi selecionados por Contini. A escolha é audaciosa já que a história da pintura italiana sugerida seria composta pelos escritos de Longhi dispostos, seguindo a ordem cronológica, por temas e sem a presença das obras. Contini se propõe a construir uma história da pintura italiana a partir de artigos do Longhi escritor, construindo uma história das formas como um percurso escondido da história oficial.

Em artigo de 18 de janeiro de 1974, Pasolini (1999, pp. 1.977-1.982) se pergunta por que Contini teria criado essa estranha antologia, desprovida de imagens e com a cronologia alterada: respondendo, ele cita uma estrutura retórica, a reticentia, que consiste na atitude de não dizer tudo que se quer dizer, uma estrutura alusiva, de chiaroscuro. E, em seguida, acrescenta ainda a técnica do scorcio, do "atalho" que não é uma visão direta, em luz plena, mas um olhar de canto, indireto e rápido. O scorcio seria, portanto, a tradução visual da reticentia. Vemos, mas não vemos o objeto por completo; falamos, mas não tudo, de maneira completa.

O scorcio é introduzido linguisticamente por uma hipótese, uma exortação ou cláusula final [...]. Lançadas ali por acaso [atiradas, como se atira algo sobre a mesa, ou sobre a mesa de jogos],$^{2}$ apressadamente, em mera função de hipótese, ou como mera conclusão de um raciocínio, as descrições dos quadros (ou melhor, da realidade representada por aqueles quadros) acabam por ser de uma exatidão lancinante, visionária (PASOLINI, 1999, p. 1.980). ${ }^{3}$

Portanto, o efeito de uma visão reduzida, parcial, produz esattezza [exatidão], lancinante, isto é, a de uma força que fere, que faz mal; e que

\footnotetext{
${ }^{2}$ Comentário do autor [N. das T.].

3 "A introdurre lo scorcio è linguisticamente un'ipotesi, o un'esortazione o una clausola finale [...]. Gettate là per caso, in fretta, in mera funzione di un'ipotesi, o a mera conclusione di un ragionamento, le descrizioni dei quadri (o, meglio, della realtà rappresentata da quei quadri) finiscono con l'essere di una esattezza lancinante, visionaria."
} 
é visionária, isto é, que transporta para um outro plano que não o da realidade. É o plano de uma outra realidade, de uma outra visão, e que é, talvez, o plano da Verdade.

Um dos truques mais conhecidos da crítica, sabemos, é o de selecionar um trecho de uma página de um autor e fazer dele a chave para ler a totalidade da obra. Esse é resumidamente o método da crítica estilística, que se fundamenta sobre o princípio filosófico do círculo hermenêutico. Eu mesmo farei uso agora dessa mesma operação, evidentemente com algumas dúvidas. Penso que o universo das últimas obras de Pasolini é como um universo fechado onde há ideias, imagens, motivos que voltam e reaparecem incessantemente, atravessando os limites entre uma obra e outra. Assim, o método do scorcio torna-se, a partir daí, o método de leitura implícito nos curtos textos que são publicados no jornal Tempo entre novembro de 1972 e janeiro de 1975 (reunidos postumamente em Descrizioni di descrizioni), isto é, durante o período mais intenso do trabalho pasoliniano, que vai da elaboração e filmagens de Canterbury a Salò, até a estreia de Salò.

Scorcio não significa, portanto, um olhar direto, mas em diagonal, o olhar de alguém que passa e que caminha rapidamente; poderíamos imaginar, para utilizar uma outra metáfora desse período, um corsário que chega, assalta e vai embora. Se quisermos procurar por afinidades, poderíamos dizer que desse modo se delineia uma leitura como prazer, de acordo com a ideia de Roland Barthes em O prazer do texto.

Há, de certo modo, algo de violento nessa atitude pasoliniana. Uma violência praticada sobre o texto, mas também praticada sobre o autor do texto. Acima de tudo direi que é a atenção à sexualidade que produz verdadeiros choques. Apenas para dar alguns exemplos, Pasolini escreve sobre Guido Gozzano:

[Gozzano] surge como um grumo de dor e aviltamento, disforme e pequeno, sem Graça natural e sem grandeza construída: a obsessão pelo sexo feminino impedia a Gozzano qualquer forma de homoerótica, isto é, da real fraternidade humana, reduzindo-o - como ele próprio sabia - a uma espécie de aleijão; o egoísmo que sempre nasce de uma doença como a tuberculose contribuíra definitivamente em delinear a incompletude humana desse homem, por outo lado, tão rico de paixão humana (PASOLINI, 1999, pp. 1.845-1.846). ${ }^{4}$

\footnotetext{
4 "[Gozzano] appare come un grumo informe e piccolo di dolore e avvilimento, senza nè Grazia naturale nè grandezza costruita: l'ossessione del sesso femminile aveva tolto a Gozzano ogni forma di omoerotia, cioè di reale fraternità umana, riducendolo - com'egli ben sapeva - un po' a un moncone; e l'egoismo che nasce sempre da una malattia come la tisi aveva contribuito a fissare definitivamente la incompletezza umana di quest'uomo d'altronde così ricco di passione umana".
} 
A propósito de Petrarca, Pasolini fala sem qualquer problema, sobre a utilização do método psicanalítico que faz do autor clássico um contemporâneo, obcecado com o narcisismo, com a automutilação, com a obsessão esquizoide e com a inibição frente ao outro sexo. Uma análise realmente atrevida! O próprio Pasolini (1999, p. 2.089) está consciente da abordagem e, ao fim de seu discurso, escreve:

Estou improvisando. Não gostaria que o leitor pensasse que fiz uma stroncatura [demolição, destruição] ${ }^{5}$ do Petrarca! Todos os seus vícios psicológicos, mal e impiedosamente elencados por mim, a sua inverossimilhança como poeta religioso, a sua insinceridade como poeta político, a que se acrescenta, enfim, a abnormidade da sua escrita que torna o Cancioneiro algo totalmente embaraçante, descrevem, sem dúvida, Petrarca como um mostro: mas é justamente por isso que ele é um grande poeta! ${ }^{6}$

Pasolini, portanto, não realiza uma operação simples, sobretudo se pensarmos que ele escreve em um jornal muito lido, e não em uma publicação especializada. Ele desconstrói as imagens tradicionais dos autores clássicos, utiliza métodos não convencionais e, depois, confirma que o autor permanece um clássico, permanece digno de consideração.

A violência exercida sobre o autor não muda o valor da obra. Nós podemos ainda considerar que a psicanálise utilizada é verdadeiramente uma psicanálise pobre, um $\mathrm{ABC}$ da psicanálise. Pasolini joga com a psicanálise como joga com os textos e com os autores. Não é simples definir esse jogo. É um jogo que não se mostra em um trecho isolado, mas que podemos acompanhar ao passar de um trecho a outro, criando linhas de continuidade entre textos diferentes.

Vimos a primeira parte desse jogo: desmascarar a figura do autor utilizando um método como o da psicanálise, que seria difundido na Itália apenas alguns anos depois, embora Pasolini já a utilizasse. Não se trata de destruir a obra, de enfraquecê-la, mas, ao contrário, de torná-la ainda mais importante, dando-lhe uma nova visibilidade associada à identidade psíquica do autor, identidade que é pobre, que é simples, e que, portanto, é possível explicar com ferramentas antigas.

\footnotetext{
${ }_{5}^{5}$ Comentário do autor [N. das T.].

6 "Sto improvvisando. E non vorrei che il lettore pensasse che io ho fatto una 'stroncatura' [éreintement, demolition] del Petrarca! Tutti i suoi vizi psicologici, da me malamente oltre che impietosamente elencati, la sua inattendibilità di poeta religioso, la sua insincerità di poeta politico, a cui va aggiunta, infine, l'abnormità della sua scrittura, che fa del Canzoniere qualcosa di addirittura imbarazzante, delineano indubbiamente il Petrarca come un mostro: ma è proprio per questo che egli è un grande poeta!"
}

Remate de Males, Campinas-SP, v.40, n.2, pp. 433-442, jul./dez. 2020 - 436 
Eis, novamente, o resultado da violência, o ato de violência: o autor é um homem como todos os demais, como todo o mundo, ele não tem nada de excepcional. Mas, além disso, o autor é alguém que procura exercer violência sobre o mundo que ele constrói, e procura ser violado por aquele que o lê. O leitor, ou o crítico, exercem violência sobre a obra, e a obra é o resultado da violência exercida sobre o mundo real. Pasolini (1999, p. 2.065) diz isso com clareza, diretamente:

Existe um momento inicial da leitura no qual o olho domina. Na verdade, sabemos, o olho é o primeiro instrumento da posse; o criador do eu como propriedade pelo ato da introjeção. Assim sendo, a leitura é, antes de mais nada, também introjeção, e o olho aí domina indiscutível. Ele vagueia pela página escrita - que é sempre uma descrição, que é, por sua vez, a afirmação de uma posse - com o frescor de um conquistador bárbaro. ${ }^{7}$

O autor é, então, exemplo de sadomasoquismo? Retornamos, portanto, à forma de sexualidade atribuída repetidamente a Pasolini? Estaria Salò já presente no ar?

É preciso maior atenção. Há uma tipologia de autor que se manifesta como violência:

[...] a violência da presença de Dante enquanto autor-personagem é pressuposta pela funcionalidade do todo, isto é pelo domínio, explícito e quase ostentado, que possui sobre a própria matéria [...]; em Gogol ocorre o contrário: a violência da própria presença do autor-personagem no livro é pressuposta pela contínua violação da funcionalidade: ele domina e é livre para fazer o que quiser (PASOLINI, 1999, p. 1.949). ${ }^{8}$

E, em sentido inverso, há uma tipologia de autor que se manifesta como doçura, vontade de desaparecer em um canto, de se fazer pequeno na presença dos outros. É o caso de Gadda:

\footnotetext{
7 "C'è un momento iniziale della lettura in cui l'occhio è padrone di tutto. Si sa infatti che l'occhio è il primo strumento del possesso; il creatore dell'io come proprietà attraverso l'introiezione. Ebbene, anche la lettura è prima di tutto un'introiezione: e l'occhio vi domina incontrastato. Esso spazia sulla pagina scritta - che è sempre una descrizione, e quindi, a sua volta, l'affermazione di un possesso - con la freschezza di un barbaro conquistatore."

8 "[...] in Dante la violenza della sua presenza in quanto autore-personaggio è presupposta dalla funzionalità di tutto, cioè dal dominio, esplicito e quasi ostentato, che egli ha sulla propria materia [...], in Gogol succede il contrario: la violenza della propria presenza di autore-personaggio nel libro è presupposta dalle continue violazioni della funzionalità: egli è il padrone ed è libero di fare tutto quello che vuole."
} 
Quando estava perto, presente, procurava se volatizar, fazer-se pequeno, desaparecer. O que era, ao final, divertido, em um homem grande como ele [...]. Um penitente, desesperadamente arrependido, com a cabeça abaixada ou reclinada, os olhos voltados para o chão, à espera de que finalmente um algoz, por ordem das veneráveis autoridades, tomasse em seus braços aquele corpanzil como se fosse um corpinho e o conduzisse ao merecido patíbulo (PASOLINI, 1999, pp. 1.808-1.809). ${ }^{9}$

Mas há ainda uma terceira forma de autor, uma forma que ele encontra em escritas mais longínquas, por assim dizer, mais simples. Como operação de método, é uma das mais ousadas. Pasolini rouba a ideia de um livro que cita diversas vezes, Thalassa de Ferenczi, um livro um pouco amalucado de um aluno herético de Freud. Pasolini retira de Thalassa a ideia de vischiosità [viscosidade], que se aplica ao coito das rãs, e afirma que há Escritas não Viscosas, isto é, escritas que não aderem ao leitor, que não colam. "O autor exprime autoridade, a autoridade é possessiva, a possessividade de um autor se manifesta através da viscosidade da sua escrita" (PASOLINI, 1999, p. 2.174). ${ }^{10}$ Elsa Morante - de quem Pasolini acabara de criticar maldosamente o romance La storia - é o exemplo de autora que produz uma escrita viscosa, possessiva. Mario Soldati (Pasolini fala de seu romance Lo smeraldo, um romance esquecido, de nossa literatura do século XX), ao contrário, é um autor que abandona a escrita possessiva. Soldati não quer possuir seu leitor, não quer sujeitá-lo. É uma forma de flexibilidade absolutamente nova. Trata-se de um tipo de fraternidade para Pasolini. E é na direção dessa fraternidade que olha. É um conceito fundamental para compreender Petrolio: através dele compreendemos a ligação entre escrita e sexualidade, a que Pasolini recorrerá em várias páginas desse livro. A vischiosità envolve o órgão sexual masculino, o falo. Soldati quer se privar desse órgão, procura - diz Pasolini - uma nova forma de relação com seu leitor, uma forma que nomeia como relação de fraternização, isto é, democrática e homossexual. Vê-se, desse modo, que estamos em presença de uma terceira versão da mesma ideia: o scorcio, a violência, a vischiosità são conceitos que conduzem ao poder

\footnotetext{
9 "Quando era vicino, presente, egli cercava di volatilizzarsi, farsi piccino, sparire. La cosa era, appunto, buffa, in un uomo grosso come lui [...]. Un penitente, disperatamente contrito, con la testa china o reclinata, gli occhi rivolti a terra, in attesta che finalmente un boia, per ordine delle venerate autorità, prendesse tra le sue braccia quel corpaccione come fosse un corpicino e lo portasse al meritato patibolo."

10 "L'autore esprime autorità, l'autorità è possessiva, la possessività di un autore si manifesta attraverso la vischiosità della sua scrittura."
} 
do autor, considerado como depositário de uma função expressiva. Eu diria que há, em muitos de seus artigos de crítica, a vontade de identificar tal poder e de elaborar estratégias para evitá-lo. No que concerne ainda a Soldati, Pasolini identifica uma figura alternativa àquela do autor poder, a figura do autor palhaço, ainda e mais uma vez, uma figura do jogo.

\begin{abstract}
Diante da privação de autoridade (que é tradicional e essencial para um autor) se vê em um estado anômalo, imponderável, fora de seus hábitos, que faz com que se desenvolvam dois instintos substitutivos ao ditatorial do autor: o instinto a se fazer passar por palhaço, isto é, a rir da sua desejada impotência ou falta de potência, e o instinto de se fazer passar pelo demônio, no mesmo sentido dostoieviskiano da palavra, isto é, organizar os jogos do palhaço de modo a lhes atribuir novamente o sentido que a grande recusa teria subtraído (PASOLINI, 1999, p. 2.175). ${ }^{11}$
\end{abstract}

Palhaço ou demônio, palhaço e demônio: essas são as duas figuras vislumbradas nesse momento. Pasolini não se pergunta o que é um autor?, mas antes em que um autor pode se tornar?, isto é, o que um autor pode ser para além da fórmula que insiste em mostrar a dimensão pobre da interioridade de um autor? Enquanto palhaço, o autor quer transformar o seu livro, a sua obra em jogo, em piada, imitando códigos literários de outros tempos. Poderíamos pensar que esse é o aspecto pós-moderno, calviniano, se quisermos, do problema. Mas acredito que não seja isso o que realmente interesse a Pasolini. Há um outro aspecto, que consiste na operação do demônio (dostoievskiano), isto é, na criação de algo indefinido, algo que deve permanecer indefinido, que não se revele como valor, isto é, como significado passível de se transformar em algo simbólico: "Naturalmente, nem mesmo o leitor chegará a entender no que consiste essa alguma outra coisa, porque a característica principal dessa alguma outra coisa é de ser sempre alguma outra coisa" (PASOLINI, 1999, p. 2.177).$^{12}$ Essa é a função da esmeralda que dá título ao romance de Soldati.

11 "Il trovarsi però privo di autorità (che è tradizionale ed essenziale per un autore) lo getta in uno stato anomalo, fuori da ogni abitudine, imponderabile, che sviluppa in lui due istinti sostitutivi a quello dittatoriale dell'autore: l'istinto a fare il pagliaccio, cioè a scherzare sulla sua voluta impotenza o mancanza di potenza, e l'istinto a fare il demone, proprio nel senso dostoevskiyano della parola, cioè a organizzare i giochi del pagliaccio in modo da riattribuire loro quel senso che 'il gran rifiuto' sembrerebbe aver loro sottratto."

${ }_{12}$ "Naturalmente, nemmeno il lettore potrà mai giungere a capire in che cosa consista questo qualcos'altro, perché la caratteristica principe di questo qualcos'altro è quella di essere sempre qualcos'altro."

Remate de Males, Campinas-SP, v.40, n.2, pp. 433-442, jul./dez. 2020 - 439 
Pasolini está à procura de algo que escapa à metalinguagem da crítica, e da crítica estilística, e da crítica psicanalítica, e da crítica marxista. Se a crítica significa identificação de valores, valores estilísticos ou históricos, para Pasolini, o risco é o da consumação rápida e irrefreável desses valores. Pode ser que ele pense que esses valores já tenham sido consumidos, que já tenhamos esgotado as obras, ou que haja um poder do mercado literário que - como vemos hoje - estabelece quais valores devem ser identificados nas obras.

Se Pasolini transitou com tamanha e admirável habilidade entre obras e autores diferentes, isso pôde se dar porque ele elabora, a cada vez, estratégias variadas para não ser vítima do mercado literário. O Poder da sociedade de massa - afirma Pasolini - relegou a literatura a uma posição subalterna. "Esse Poder [...] na realidade, não sabe mais o que fazer com a literatura." (PASOLINI, 1999, p. 1.967) ${ }^{13}$ O mesmo destino da crítica: os críticos colocaram-se a serviço do poder, compõem o jogo de poder e elaboram um discurso que não concerne à literatura, mas à função social dos livros lançados: "Se fala sobre um livro porque a moda, a editora, o diretor do jornal, a posição literária ou ideológica coincidente [...] querem que se fale" (p. 1.969). ${ }^{14}$

Podemos pensar que essa alguma outra coisa, esse algo a mais, que continua sempre alguma outra coisa, um algo a mais, é semelhante ao sentido obtuso de que fala Roland Barthes, em leitura dos fotogramas de Eisenstein no ensaio $O$ terceiro sentido.

Talvez Pasolini tenha lido as páginas de Barthes. Mas, ao ler as descrições de descrições, percebemos que essa alguma outra coisa não permanece vazia, não permanece indefinida. Pasolini deixa para trás todas as técnicas de análise que conhece: a estilística, o estruturalismo, a psicanálise, para depois, em cada obra, fazer considerações que não concernem somente à obra, mas ao mundo em sua complexidade. Através da obra, pode-se ver o mundo, e então o que se vislumbra não é mais a Verdade, mas uma nova Realidade: Maurice, o romance de Foster, nos faz ver de maneira diferente a relação entre a classe social burguesa e a classe popular, se o encaramos através do erotismo; o romance de Huysmans, Às avessas, expõe o mecanismo da cultura burguesa que conduz ao suicídio, isto é, à autodestruição por excesso de cultura que está na raiz de dois

\footnotetext{
${ }_{13}$ "Questo Potere [...] in realtà, non sa più cosa farsene della letteratura."

${ }_{14}$ "Di un libro si parla perché la moda, la casa editrice, il direttore del giornale, la comune posizione letteraria o ideologica ... vogliono che se ne parli."
} 
fenômenos opostos, o nazismo e a revolução hippie: “[...] em ambos os casos uma força diabólica e autopunitiva nasce da Razão burguesa, e se lança sobre ela para destruí-la" (PASOLINI, 1999, p. 1.746);15 em um romance menor do século XIX, L'eredità Ferramonti, de Gaetano Carlo Chelli, a personagem de Paolo anuncia o homem de poder burguês da política italiana, "o modelo real dos homens que realizariam a história italiana” (PASOLINI, 1999, p. 1.766). ${ }^{16}$

A crítica é também uma forma de denúncia do poder da nova sociedade do neocapitalismo. É por isso que, frequentemente, Pasolini procura identificar formas de expressão que não podem ser utilizadas por esse poder, formas que escapam à própria crítica. E, então, fala que em Cidades invisíveis, de Calvino, o sentido é "[...] como um eco num vale repleto de grutas que soa aqui e ali, embora seja sempre o mesmo" (PASOLINI, 1999, p. 1.728), ${ }^{17}$ isto é, o efeito do eco, a ecolalia, ou então fala da acumulação como princípio que confere expressividade à página pornográfica de Sade, que não é expressiva por si só, e em seguida ele encontra na poesia de Giorgio Baffo, um poeta italiano do século XVIII, o mesmo efeito de acumulação que produz "um deserto de tal modo insípido que não oferece ao olhar alucinado sequer um mínimo fio de grama" (PASOLINI, 1999, p. 2.161). ${ }^{18}$ Assim, o que se recuperaria em todas essas páginas seria o vazio, o ilegível, apenas efeitos de repetições?

A verdadeira face da crítica revela-se como a vontade de não respeitar qualquer verdadeiro princípio crítico. Maneirismo e pastiche são os dois princípios que sempre animam os trechos, as descrições. Paradoxo, oximoro, inversão são as estratégias retóricas mais utilizadas. Enfim, as Descrizioni são um grande banquete satírico, um prato cheio, uma sátira perspicaz. Ao escrever sobre uma obra de Contini que é o duplo da obra de Longhi criada por Contini, isto é, uma história da literatura italiana dos séculos XIX e XX (jamais escrita por Contini, mas criada por seus alunos), Pasolini diz que se pode falar de um escândalo, e que o verdadeiro escândalo consiste na relação entre Contini e Gramsci. Mas há uma relação entre Contini e Gramsci? Não sei. Continuando o artigo,

\footnotetext{
15 " [...] in ambedue i casi una forza diabolica e autopunitiva nasce dalla Ragione borghese, e si lancia su di essa per distruggerla”.

16 "[...] il modello reale degli uomini che avrebbero fatto la storia italiana".

${ }_{17}$ "[...] è come un'eco in una valle piena di grotte che suona ora qua ora là, pur essendo sempre lo stesso".

18 " [...] un deserto talmente piatto da non offrire allo sguardo allucinato neanche il minimo filo d'erba”.
}

Remate de Males, Campinas-SP, v.4o, n.2, pp. 433-442, jul./dez. 2020 - 441 
em uma nova acrobacia, Pasolini desloca o discurso para um pequeno livro de Alberto Arbasino, Specchio delle mie brame, que é um roteiro, um romance em forma de roteiro. Fala de uma escrita que tem origem no desejo de provocar uma forma de riso cômico, como o que se encontra também em Dostoievski. O que é o riso? "O riso provocado por Arbasino corresponde a anasyrma [...], isto é, a abaixar as calças (ou as saias) e mostrar os genitais." (PASOLINI, 1999, p. 2.207) (19 $^{19}$ crítica de Pasolini é um ato obsceno, é um ato que quer mostrar as genitais dos textos, ou - melhor - dos autores. Como o próprio Pasolini havia escrito, é sob o signo de Tétis, isto é, da sexualidade, que nascem os ensaios literários: "Nos ensaios ideológicos uso meu senso comum/só naqueles poéticos, oh Tétis, o meu acume" (p. 2.979). ${ }^{20}$ Tudo isso que lemos em Descrizioni di descrizioni encontra-se em Petrolio e Salò. Toda crítica é criação. Toda criação é destruição.

\author{
Tradução de Nina Borges Amaral21 \\ e Maria Betânia Amoroso 22
}

\title{
REFERÊNCIAS
}

PASOLINI, Pier Paolo. Saggi sulla Letteratura e sull'Arte. Org. Walter Siti e Silvia De Laude. Vol. II. Milão: Arnoldo Mondadori, 1999.

Recebido: $13 / 8 / 2020$

Aceito: 19/8/2020

Publicado: 12/11/2020

\footnotetext{
19 "Il riso suscitato da Arbasino corrisponde [...] all'anasyrma, cioè il tirarsi giù i calzoni (o su le sottane) e mostrare i genitali [...]".

${ }_{20}$ "Nei saggi ideologici ci metto il mio senso comune / solo per quelli poetici, oh Tetis, il mio acume".

${ }^{21}<$ ninabamaral@gmail.com>.

${ }^{22}$ Professora Colaboradora do Departamento de Teoria e História Literária do Instituto de Estudos da Linguagem, Universidade Estadual de Campinas, Brasil: <betamor@uol.com.br> . 